\title{
Inclusive Higher Education for Students with Disabilities in China: What Do the University Teachers Think?
}

\author{
Yuexin Zhang ${ }^{1}$, Sandra Rosen ${ }^{2}, \mathrm{Li}_{\text {Cheng }}{ }^{1} \&$ Jingshan $\mathrm{Li}^{3}$ \\ ${ }^{1}$ Institute of Special Education, Faculty of Education, Beijing Normal University, China \\ ${ }^{2}$ Department of Special Education, San Francisco State University, USA \\ ${ }^{3}$ Beijing Beichen Fudi Kindergarten, China \\ Correspondence: Li Cheng, 19 Xinjiekouwai St., Beijing, China. E-mail: 11112014077@ bnu.edu.cn
}

Received: September 6, 2018

Accepted: September 21, $2018 \quad$ Online Published: October 19, 2018

doi:10.5539/hes.v8n4p104

URL: https://doi.org/10.5539/hes.v8n4p104

\begin{abstract}
Inclusive higher education is a path to protect the educational rights of university students with disabilities. University teachers' attitudes toward students with disabilities, and towards their inclusion in universities, are a key factor that will affect the development of inclusive higher education. This study used a questionnaire to explore an overall perspective of how university teachers in China view inclusive higher education from emotional, cognitional and conative aspects. Their responses suggest that university teachers in China have positive emotion and cognition toward the rights of students with disabilities to receive higher education; the teachers do, however, appear to lack motivation, relevant knowledge, skills, and effective strategies to cope with the students' special needs. This suggests that effective implementation of inclusive higher education must be supported by an effective service center for those who have disabilities, a support network of professionals, and an administrative support system for teachers and students.
\end{abstract}

Keywords: inclusive higher education, students with disabilities, attitudes, university teachers

\section{Introduction}

\subsection{Inclusive Education: CRPD and the Chinese Regulations}

The expression "inclusion" came into wide use in China in the late 1980's. Discussion regarding inclusive education typically concerned equitable access and participation of students with disabilities (SwDs) in education at elementary and middle school levels. The United Nations (2006) Convention on the Rights of Persons with Disabilities (CRPD) states that "persons with disabilities are able to access general tertiary education, vocational training, adult education and lifelong learning without discrimination and on an equal basis with others." With the Ratification of the CRPD, China has made a concerted effort, both in policy and in practice, to protect and improve the educational rights of people with disabilities. The "Outline of national medium and long-term educational planning and development (2010-2020)" and the two-phrases "Promotion plan of special education" of 2014-2016 and 2017-2020, are seen as the most important (special) educational regulations in China in the $21^{\text {st }}$ Century, and improving inclusive education is a major concern throughout the entire educational system in China. To protect the rights to higher education for SwDs is innately a large task.

\subsection{Higher Education for Students with Disabilities in China}

In China, access to higher education for SwDs commenced in the 1980s with two types of programs being available. Specific majors at regular universities (Note 1), or at special education colleges, admitted students who have visual impairments, deafness or hearing loss, or physical disabilities. Students with sensory or physical disabilities, who have fewer academic support-needs, take the unified national university entrance examination (Gao Kao) to gain admission to regular universities. Until 2010, there were 30,000 SwDs in regular universities which was 8 to 10 times greater than the number of those attending special education colleges (Xu, 2012).

Integrated higher education is gradually becoming the primary channel for SwDs to be enrolled in higher education in China (Xu, 2012). According to the Chinese Ministry of Education (2015), a total of 9,542 SwDs were admitted to higher education, and of these 7,864 were attending regular universities in 2014. Although there are increasing numbers of SwDs attending universities, the societal and governmental discourse regarding 
relevant policies in China has had far less focus on accessible and inclusive higher education than inclusive elementary and middle school education.

Developing inclusive higher education requires an understanding of the philosophical, political, pedagogical, and contextual factors which either substantiate or hinder access and participation for individuals with disabilities. Improving higher education exam policy might be the first step to achieving this aim. In 2015, there was a milestone event in the history of the "Gao Kao" - SwDs who graduate from special schools were given the right to take the university entrance examination with accommodations for disability (Chinese Ministry of Education, 2015). However, access to higher education for SwDs in regular universities is still somewhat restricted. Until recently, the call for inclusive education has not had any profound influence on the policies of universities. Compared to faculty at special education colleges, most regular university teachers and staff lack specific knowledge about teaching students with disabilities (Chu \& Xu, 2007; Ma, 2014). Although there are increasing numbers of SwDs attending regular universities, most regular universities have not taken any effective supportive measures or provided any exceptional accommodations to help integrate SwDs into university classroom education (Ma, 2014).

\subsection{Attitudes of University Teachers as One of the Most Influential Factors for Inclusive Higher Education}

There are various barriers that prevent equitable access to education or that hinder quality of education for people with disabilities, including the tangible factors (such as barrier-free infrastructure and other reasonable accommodations) and those considered intangibles (Sánchez, Fernández-Jiménez, \& Cabezas, 2018). One of the intangible factors that strongly influences the implementation of inclusive education is the attitudes of the community. Therefore, attitudes towards inclusive education for people with disabilities have been given progressively larger amounts of attention (e.g., Ashman, 1984; Peng, 1999; Salend \& Duhaney, 1999; Cook, Tankersley, Cook, \& Landrum, 2000; Peng, 2000; Cook, 2001; Palmer, Fuller, Arora, \& Nelson, 2001; Ju, 2014; $\mathrm{Ma}, 2014)$. Inclusive higher education is an important element of inclusive education. University teachers' attitudes towards inclusive higher education have also received increased attention.

Existing research has concluded that university teachers are the key to the support system and play a very significant role in the course of developing inclusive higher education (Zhang et al., 2010; Sánchez et al., 2018). However, Chinese higher education research studies regarding SwDs are still in the growing stages. Most of them have concentrated on the theoretical research and the overall development strategy for inclusive higher education (Bian, Teng, \& Zhang, 2012). Some research focused specifically on teachers from special education colleges (Bian et al., 2012; Teng, 2011). However, regular university teachers and their attitudes towards inclusive higher education has not been examined closely. Based upon the few Chinese studies to date, regular university teachers have not had significant exposure to relevant policies about inclusive educational rights of people with disabilities (Ma, 2014); they have less awareness of the special needs of students (Chu \& Xu, 2007), sometimes treat them unjustly (Ma, 2014), and lack special education knowledge and skills (e.g., Zong, 2005; Bian et al., 2012; Ju, 2014). In terms of students who have hearing loss or who have a visual impairment, Ju (2014) pointed out that regular university teachers do not know about sign language or braille. Realistically, requiring every regular university teacher to be a professional special educator may be impossible and not a necessity. It is unrealistic to ask all of them to learn sign language and braille. However, professionals with specialized skills could support university teachers by educating them on a variety of strategies to teach those with SwDs (e.g., transferring printed materials to digital format for blind students instead of translating it in braille, or even providing deaf students PowerPoint material rather than just relying on communication via sign language).

Relevant research from abroad has analyzed the impact of the knowledge of university teachers on inclusive higher education from several aspects including: how much, if anything, they know about disability policies and law (Villarreal, 2002; Rao \& Gartin, 2003; Vasek, 2005), what are their attitudes toward SwDs (Vogel, Leyser, Wyland, \& Brulle, 1999; Rao, 2004) and their experience and perceptions about teaching SwDs (Burgstahler, Duclos, \& Turcotte, 2000; Berry \& Mellard, 2002; Hadjikakou \& Hartas, 2008), and assessment of the existing support systems of universities (Burgstahler et al., 2000; Bourke, Strehorn, \& Silver, 2000; Berry \& Mellard, 2002; Riddell et al., 2007). The research of Rao and Gartin (2003) found that university teachers' knowledge of relevant laws and policies pertaining to SwDs, were positively linked to whether they would offer accommodations (Rao \& Gartin, 2003). For the most part, however, their understanding levels were generally low (Wilson, Getzel, \& Brown, 2000; Villarreal, 2002), and almost half of them had minimal or no related knowledge (Vasek, 2005). Teachers' perspectives on whether SwDs should receive accommodations during study and examination times varied. Some thought it is reasonable, while others thought it may be unfair, placing non-disabled students at a disadvantage (Vasek, 2005). Berry and Mellard (2002) found in their study that 
university teachers did not think they had sufficient time to give extra services to SwDs. Other studies however, have suggested that university teachers would like to provide extra services to SwDs if they had adequate time (Sweener, Kundert, May, \& Quinn, 2002; Vogel et al., 1999).

Furthermore, researchers found that teachers who have teaching experience with SwDs were more welcoming of, and sympathetic toward, inclusive higher education (Burgstahler et al., 2000). They saw the students' diversity as a chance to enhance the atmosphere of the university. They felt that teaching SwDs would motivate teachers to reflect on how to change their teaching tactics to deal with diversity.

Other studies explored the situation of higher inclusive education from the view of SwDs (e.g., Hanafin, Shevlin, Kenny, \& Mc Neela, 2007; Hadjikakou \& Hartas, 2008). For example, Hanafin et al. (2007) implemented a small-scale qualitative research procedure designed to articulate the experiences of two groups of SwDs in two higher education institutions. One group included students with physical disabilities, and the other group included students with dyslexia. Negative attitudes of university teachers and other students were the greatest barriers that were reported by participants. The participants also stated that the physical environment was inadequately adapted to ensure full inclusion; their access to lecturers' notes was inconsistent; assistive personnel and technology were delivered too late, and inappropriately.

While notable research from abroad has been done on inclusive higher education, Chinese researchers have rarely focused on regular university teachers' attitudes towards inclusive higher education. Furthermore, the cultural and political contexts in the western studies are very different from those in China. Therefore, this study will focus on regular university teachers in China and consider inclusive higher education explicitly in the cultural and political contexts of Chinese society. The specific purpose of this study is to review the attitudes of regular university teachers toward higher education rights for SwDs, their perception of the influential factors for applying inclusive higher education, as well as their practices and methods in teaching SwDs.

\section{Method}

\subsection{Questionnaire}

This study used a self-compiled questionnaire, "Perceptions of university teachers towards inclusive higher education" as the main tool. It was developed originally by Susanne Peschke (Note 2.) from the University of Hamburg and was modified by the authors to be suitable in the Chinese cultural context. Peschke's research focused mainly on comparative inclusive higher education. She developed her questionnaire to investigate the attitudes of university teachers toward inclusive higher education for SwDs in different cultural contexts, such as Germany, Spain, the U.S. and Taiwan.

This questionnaire is based on the three components that form the structure of attitude: emotion, cognition and behavior (Triandis, 1971). According to Triandis (1971), the affective component includes the emotional aspect, (e.g., the positive or negative views, pleasant or unpleasant emotions, motivations and subjective assessments of the individual against a standard. The cognitive component relates to a specific way in which the objective person is being perceived. It includes opinions, thoughts, perceptions, beliefs, conclusions and evaluative judgments of the individual against a certain standard. And the conative component focuses on the actions toward, or treatment of, an individual related to a standard.

In addition to the basic information of the respondents, such as gender, age, and years of teaching experience, the main questions of the questionnaire were based on the above mentioned "three components theory" of attitude and included six questions. Questions related to the "emotional component" were: (1) acceptance of different types of disability/ ranking of the most restrictive disability types in regular universities, and (2) acceptance of different forms of higher education for SwDs. Questions related to the "cognitive component" were: (1) perception of stakeholders in developing inclusive higher education, and (2) perception of preferential admission policy for SwDs. Questions related to the "conative component" were: (1) what accommodations and support should universities provide to meet the special needs of SwDs, and (2) teachers' self-evaluation about their own inclusive teaching practices.

In order to better applying the questionnaire to this study, we conducted interviews during the "China-Germany workshop on inclusive higher education", which was held at the university where the primary author worked in 2016. Altogether 21 students from institute of special education and 13 university teachers from different universities were enrolled. Two group interviews with students and teachers were conducted separately to explore their general perception about inclusive higher education for SwD. According to the interviews, the participating teachers expressed generally more uncertainties and worries than students, even though some of the teachers had a professional background in special education. And most of the worries they mentioned were 
consistent with the survey questions of the questionnaire. Therefore, the present study adopted most of the questions of the original questionnaire; only a few options of questions, which are not applicable to the Chinese cultural context, were modified or deleted.

\subsection{Samples}

This study mainly focused on inclusive higher education, so the respondents were therefore chosen from regular universities, rather than from special education colleges. Meanwhile, the emerging levels of the participating universities were considered. In this study, universities who have enrolled SwDs for many years, and universities without such experience were both chosen. Furthermore, since the idea of inclusive higher education is still a new concept in Chinese higher education, the respondents included primarily those who had an academic background of pedagogy.

E-mails, with questionnaires and informed consent attached, were sent to the secretaries of faculty of education of nine universities. They were asked to forward the questionnaire to teachers. However, only 90 questionnaires with full information were returned from nine universities, which included Tongji University (TU), Beijing Normal University (BNU), Central China Normal University (CCNU), Sichuan University (SU), North-western University (NU), Minzu University of China (MUC), Hangzhou Normal University (HZNU), Renmin University of China (RUC), and Hubei University (HU). The demographic variables based on the valid sample are shown in Table 1.

Table 1. Demographic variables

\begin{tabular}{llllll}
\hline Variable & $\boldsymbol{N}$ & $\mathbf{\%}$ & Variable & $\boldsymbol{N}$ & $\mathbf{\%}$ \\
\hline University & $\mathbf{9 0}$ & & Gender & $\mathbf{9 0}$ & \\
\hline BNU & 32 & $35.6 \%$ & M & 44 & $48.9 \%$ \\
CCNU & 15 & $16.7 \%$ & F & 42 & $46.7 \%$ \\
MUC & 12 & $13.3 \%$ & Missing & 4 & $4.4 \%$ \\
HU & 7 & $7.8 \%$ & Age & $\mathbf{9 0}$ & \\
NU & 6 & $6.7 \%$ & $\leq 34$ & 33 & $36.7 \%$ \\
TU & 5 & $5.6 \%$ & $\geq 35$ & 54 & $60.0 \%$ \\
HZNU & 5 & $5.6 \%$ & & & \\
RUC & 4 & $4.4 \%$ & & & \\
SU & 4 & $4.4 \%$ & Missing & 3 & $0.3 \%$ \\
Position & $\mathbf{9 0}$ & & Years of teaching experience & $\mathbf{9 0}$ & \\
Lecturer & 32 & $35.6 \%$ & $1-5$ & 33 & $36.7 \%$ \\
Assoc. Professor & 23 & $25.6 \%$ & $6-10$ & 28 & $31.1 \%$ \\
Professor & 15 & $16.7 \%$ & $11-15$ & 13 & $14.4 \%$ \\
Research-fellow & 12 & $13.9 \%$ & $16-20$ & 6 & $6.7 \%$ \\
Missing & 8 & $8.9 \%$ & $\geq 21$ & 6 & $6.7 \%$ \\
& & & Missing & 4 & $4.4 \%$ \\
\hline
\end{tabular}

\section{Results}

The results are presented below according to the survey questions of the questionnaire.

\subsection{Disability Types which can be Restrictive in College Life}

In this question, respondents were asked to choose which types of disability can be restrictive in the students' college life. Eight types of disabilities were listed for choosing, which included: visual impairment, deafness or hearing loss, psychiatric disorder, physical disability, learning disability, speech disorder, chronic illness and multiple disabilities. Excluding learning disability and chronic illness, the rest are disability types by law in China.

Table 2 portrays the frequency of responses to the various disability types. The rate of respondents choosing 'psychiatric disorder' was the highest. Conversely, the least respondents considered that 'chronic illnesses' were restrictive. The numbers of respondents who chose 'visual impairment' and 'Deaf or hard-of-hearing' were ranked second and third, respectively. 
Table 2. Most restrictive disabilities in regular university

\begin{tabular}{lll}
\hline \multirow{2}{*}{ Type of disabilities } & Responses \\
\cline { 2 - 3 } & Frequency & Percent \\
\hline Psychiatric disorder & 73 & $16.90 \%$ \\
Visual impairment & 66 & $15.20 \%$ \\
Deaf/ hard-of-hearing & 64 & $14.80 \%$ \\
Multiple disability & 60 & $13.90 \%$ \\
Learning disability & 55 & $12.70 \%$ \\
Speech disorder & 47 & $10.90 \%$ \\
Physical disability & 43 & $9.9 \%$ \\
Chronic illness & 25 & $5.80 \%$ \\
Total & 433 & $100.00 \%$ \\
\hline
\end{tabular}

\subsection{Acceptance of Different Forms of Higher Education for Students with Disabilities}

As explained in the introduction, there is more than one form of higher education for SwDs in China. In this questionnaire, numerous choices were provided, although a few of them are still not popular in China. The options included: (1) Some regular universities creating specific majors, such as acupuncture, which are considered to be suitable for SwDs, but which are also accessible to all students. (2) Some regular universities making specific majors available to students who have certain types of disabilities, such as information technology for students with hearing loss or visual impairment. (3) Distance education. (4) All regular universities allowing SwDs to enroll in all majors. (5) Special education colleges. (6) Regular universities creating specific majors which enroll only SwDs. A final option available for respondents to choose was "I have no idea." As is shown in table 3, many university teachers preferred that regular universities create specific majors, where the curriculum and learning resources are adequate for students with certain disabilities, and yet would also be offered equally to students without disabilities $(25.9 \%)$. The next preference was distance learning/ Internet course (17.3\%). The third preference pertained to regular universities enrolling students with certain disability types, with SwDs being limited to specific majors (16.8\%). Only $14.2 \%$ of teachers agreed that all regular universities and all majors should be open for SwDs. Furthermore, most teachers didn't support setting up additional majors specifically for SwDs. These results illustrate that teachers do not consider "isolation" of SwDs in regular universities as a prudent option.

Table 3. Preferred forms of offering higher education for SwDs

\begin{tabular}{lll}
\hline Types of options & Frequency & Percent \\
\hline Regular universities create specific majors open to all students & 51 & $25.9 \%$ \\
Internet courses/distance learning & 34 & $17.3 \%$ \\
Regular universities enroll students with certain & 33 & $16.8 \%$ \\
disability types in & & \\
some specific majors & & \\
All regular university majors are open to SwDs & 28 & $14.2 \%$ \\
Special education colleges & 26 & $13.2 \%$ \\
Regular universities create majors exclusively for SwDs & 16 & $8.1 \%$ \\
Have no idea & 9 & $4.6 \%$ \\
Total & 197 & $100.00 \%$ \\
\hline
\end{tabular}

\subsection{Understanding of Preferential Admission Policy}

This multiple choice question was aimed at surveying participants' understanding of preferential admission for SwDs. Besides SwDs, other types of students were listed in the options. These types included students from disadvantaged families, students with babies, foreign students, students who graduated from vocational or technical secondary school, and students with artistic or sports specialties (Note 3). Respondents were required to select which types of students should have preference for admission. The frequencies of responses are shown as percentages in the table in Table 4. 
Table 4. Types of students who should have priority at admission

\begin{tabular}{lll}
\hline Types of Options & Frequency & Percent \\
\hline Students with disabilities & 55 & $38.2 \%$ \\
Students from disadvantaged families & 30 & $20.8 \%$ \\
All students treated equally & 29 & $20.1 \%$ \\
Students having artistic or sports specialty & 13 & $9.0 \%$ \\
Graduates from vocational or technical secondary schools & 7 & $4.9 \%$ \\
Foreign students & 5 & $3.5 \%$ \\
Students with babies & 3 & $2.1 \%$ \\
Missing & 2 & $1.4 \%$ \\
Total & 144 & $100.00 \%$ \\
\hline
\end{tabular}

Data showed that respondents had a high agreement on preferential policy for 'students with disabilities' and 'students from disadvantaged families', and low agreement on preferential policy for 'students with babies' and 'foreign students.' These data indicate that university teachers think that 'students with disabilities' and 'students from disadvantaged families' have fewer social resources and should have priority in placement opportunities.

\subsection{Perception of Stakeholder in Developing Inclusive Higher Education}

This question asked the participants to identify the primary stakeholders for inclusive higher education. It was an orientation-ranking question which had eight options: university administrative management system, a service center for SwDs, students with disabilities, all university students, university teachers, administrators, representatives of organizations for students, and representatives of organization for SwDs. Respondents were required to select three options and rank them from 1-3, with 1 meaning the most important. When analyzing the data, weighted values for the rankings were made first and then the data were re-coded. For example, the weighted values of options ranked 1,2,3 were 5,3,1 respectively.

Results showed that university teachers paid the most attention to the management system's influence on developing inclusive higher education, followed by university administrators and service centers for SwDs, respectively (Table 5).

Table 5. Ranking list of factors and stakeholders in developing inclusive university

\begin{tabular}{lllllllll}
\hline Rank & Options & Case 1 & Case 2 & Case 3 & Case 4 & Case ...5 & SUM & Percent \\
\hline 1 & Management system & 5 & 5 & 5 & 3 & 3 & 307 & $19.46 \%$ \\
2 & University administrators & 0 & 0 & 0 & 0 & 5 & 248 & $15.71 \%$ \\
3 & Service center for SwDs & 0 & 3 & 0 & 0 & 1 & 216 & $13.69 \%$ \\
4 & University teachers & 1 & 0 & 1 & 5 & 0 & 205 & $12.99 \%$ \\
5 & All university students & 3 & 0 & 3 & 1 & 0 & 184 & $11.66 \%$ \\
6 & Students with disabilities & 0 & 0 & 0 & 0 & 0 & 150 & $9.51 \%$ \\
7 & $\begin{array}{l}\text { Representative of } \\
\text { organization for SwDs }\end{array}$ & 0 & 1 & 0 & 0 & 0 & 148 & $9.38 \%$ \\
8 & $\begin{array}{l}\text { Representative of } \\
\text { organization for all students }\end{array}$ & 0 & 0 & 0 & 0 & 0 & 124 & $7.86 \%$ \\
\hline
\end{tabular}

\subsection{How to Fulfill the Special Needs of Students with Disabilities?}

This question in the original questionnaire included detailed options of the support and services provided to SwDs. As shown in Table 6, all of the support and services were categorized into four aspects: counselling/support for beginners and job placement, learning environment support, financial support and instructional support for teachers.

Counseling/support for beginners and job placement include three specific aspects: priority at admission, campus orientation, and specific career planning. Learning environment support mainly included six items: barrier-free environments in the classroom, individual study assistants, reading assistants, writing assistants, accessible media, and accessible texts. Extra financial support was also touched upon in this study. Instructional support for teachers was subdivided into two main aspects, namely teaching equipment and resources, as well as ensuring full participation of SwDs in class. In these regards, there were ten concrete items as follows: accessible teaching materials, learning strategies, assistance in completing course work, variety of exam forms, extended time for exams, substituted exam content, substituted course content, decreased course content, priority of selecting 
courses, and guidebooks for SwDs.

Table 6. Importance of University supports and services for SwDs

\begin{tabular}{lll}
\hline Types of supports and services & $\boldsymbol{N}$ & Percent \\
\hline Support for beginners and job placement & 42 & $36.40 \%$ \\
Learning environment support & 30.17 & $26.15 \%$ \\
Extra financial support & 23 & $19.94 \%$ \\
Instructional support for teachers & 20.2 & $17.51 \%$ \\
Total & 115.37 & $100.00 \%$ \\
\hline
\end{tabular}

\subsection{Teachers'Self-evaluation of Their Own Inclusive Teaching Practice}

Twelve items were designed to investigate whether teachers were anxious about implementing inclusive educational concepts in their day-to-day teaching practices. Examples presented to the teachers included: providing lecture and teaching materials in accessible format; whether teaching styles were, or were not, suitable for all students; whether students' special needs were, or were not, discussed at the beginning of semester, etc. The respondents were given the options, "no", "unclear" and "yes", and asked to respond to each category based upon their own experience. The answers were coded by "-1", "0" and "1" respectively (Table 7).

Table 7. Teachers' evaluation of their own inclusive teaching practice

\begin{tabular}{llllll}
\hline & & \multicolumn{2}{c}{ SUM } & \\
\hline & Frequency & Percent & Valid Percent & Cumulative Percent & Frequency \\
\hline Valid & -6.00 & 3 & 3.4 & 3.4 & 3.4 \\
& -5.00 & 1 & 1.1 & 1.1 & 4.6 \\
& -4.00 & 4 & 4.5 & 4.6 & 9.2 \\
& -3.00 & 4 & 4.5 & 4.6 & 13.8 \\
& -2.00 & 10 & 11.4 & 11.5 & 25.3 \\
& -1.00 & 8 & 9.1 & 9.2 & 34.5 \\
& .00 & 8 & 9.1 & 9.2 & 43.7 \\
& 1.00 & 9 & 10.2 & 10.3 & 54.0 \\
& 2.00 & 9 & 10.2 & 10.3 & 64.4 \\
& 3.00 & 7 & 8.0 & 8.0 & 80.4 \\
& 4.00 & 7 & 8.0 & 8.0 & 83.9 \\
& 5.00 & 3 & 3.4 & 3.4 & 93.1 \\
& 6.00 & 8 & 9.1 & 9.2 & 100.0 \\
& 7.00 & 3 & 3.4 & 3.4 & \\
Missing & 10.00 & 3 & 3.4 & 3.4 & \\
\hline
\end{tabular}

The results showed that teachers had low evaluations of their own inclusive teaching practice, with the lowest score being -6 ; only six teachers scored higher than 7 , which represented $6.8 \%$ of the total.

A different analysis was made according to demographic variables such as gender and age. Since there were only a few respondents under 25 or over 54 years old, the sample was then divided into two groups, namely groups "under 34" and "over 35" years of age. The results showed that there was no significant difference between gender, age, years of teaching, and subject area.

\section{Discussion}

\subsection{Acceptance of Different Types of Disability}

Pre-existing research has found that university teachers are most motivated to accept students with apparent physiological disabilities, such as physical disability, deafness or hearing loss (Baggett, 1994), and visual impairment (Gitlow, 2001). Conversely, students with psychiatric disorders or emotional-behavioral disorders are most ostracized (e.g., Gitlow, 2001; Burgstahler et al., 2000; Berry \& Mellard, 2002; Wolman, McCrink, Rodriguez, \& Harris-Looby, 2004). In the present study, respondents generally regarded psychiatric disorders, hearing loss and visual impairment as the three disabilities which most likely make students' college life 
restrictive. People in different cultures are always under the impression that those with psychiatric disorders might jeopardize the safety of other people (Link, Phelan, Bresnahan, Stueve, \& Pescosolido, 1999; Angermeyer $\&$ Matschinger, 2005). Students with visual impairments or hearing loss may face challenges because they need accommodations such as a typing assistant and Braille materials, yet most regular universities in China lack experts and the additional resources to provide adequate assistance to these students. Compared to students with the above-mentioned three disabilities, chronic illness was not regarded as a disability according to the disability classification by the Standardization Administration of the People's Republic of China (2011). This study reflected that few teachers attributed the difficulties of inclusion of SwDs to the barriers of the campus's environment or inaccessible curricula.

\subsection{Understanding Forms of Higher Education for Students with Disabilities}

In 2015, Chinese SwDs who graduated from special schools gained the right to take the national university entrance examination (Gao Kao) and to have necessary accommodations such as visual aids, hearing aids, or a braille printer, during the examination. With this new policy, it is predicted that more and more students who are visually impaired or who have a hearing loss will take this examination as time goes on. However, universities do place limits on admission eligibility of SwDs. Specifically, there may be some restrictions placed on students who have more acute sensory or physical conditions. In Ma's (2014) research, 30.7\% of the respondents thought many majors in regular universities were made unavailable to those who have disabilities, and that SwDs had only a few options of majors from which to select. In connection with this conclusion, this current study aimed to know what teachers consider to be the most suitable placements for SwDs wishing to receive a higher education. In general, the respondents' understandings of inclusive higher education were still ambiguous. On the one hand, they thought SwDs would be unable to finish higher education because of their own limitations; on the other hand, they agreed that SwDs had the right to study at regular universities. Thus, the two options that were regarded as the best approaches to making SwDs inclusive were: 1) Having regular universities create specific majors, where the curriculum and learning resources would be adequate accessible to students with certain disabilities, yet also be offered to students without disabilities; 2) Regular universities enroll students with certain disabilities in specific majors only. These responses imply that SwDs would be welcome to study at regular universities, but in reality limitations and boundaries still exist and there is not true inclusion. In essence, SwDs can't choose from all majors offered.

\subsection{Key Stakeholders of Developing an Inclusive University}

University teachers understand the most vital three elements in developing an inclusive university are "administrative management system", "university administrator" and "service center for SwDs". Ma (2014) suggested a comprehensive support system to guarantee inclusive higher education, which includes such things as support systems for the management of SwDs affairs, teaching management, research management and effective transition systems. It is easy to see that the administrative management system is a large portion of the whole system. Xu (2008) pointed out that the university leaders play a vital role and carry out the main tasks. This point of view is congruent with the results of our study, that university teachers view administrative management systems as having the greatest influence in developing inclusive higher education. In addition, teachers understood the importance of a "service center for SwDs", though such centers are still sporadic in Chinese universities.

\subsection{Accommodation and Support for Students with Disabilities}

Setting up a support system is the premise for successful inclusive higher education. The results of this study illustrate that with regard to a support system 'support for beginners' and 'job placement' were regarded as the most imperative considerations for SwDs. Next were "campus environmental support" and "extra financial support", while the importance of "teaching management support" was ignored. The results showed that universities mostly focused on admission and employment of SwDs, while they paid little attention to students' adaptation and integration into campus life and study. This was similar to the research of Hadjikakou and Hartas (2008). Hadjikakou and Hartas interviewed 14 university tutors and senior managers about their perceptions of accommodations for SwDs. Some tutors stated that teaching modification was intolerable due to the rapid pace of lessons and the financial cost of such accommodation (e.g., the employment of an interpreter). Farmer, Riddick and Sterling (2002) pointed out that support of SwDs in higher education must be measured at three levels - namely personal, organizational/institutional and political/ideological. Personal pertained to providing counseling services, adjusting the curriculum, adapting teaching and other services such as using a sign language interpreter or providing materials in Braille. Organizational pertained to simplifying institutional procedures, training staff and modifying the physical environment. Finally, ideological pertained to debating models of 
disability and current policies, striving for equality of opportunity and supporting students' access and entitlement to education. This study suggested that sustaining instructional support for teachers is the most direct and important factor in supporting students' academic development; without this, the education of SwDs would be undesirably prejudiced and the graduation rates, as well as the employment situation, would also be affected negatively. Therefore, university support for SwDs should not only focus on admission and job placement, but also on academic support for SwDs at a university.

\subsection{Teachers'Self-evaluation of Inclusive Teaching Practice}

In general, teachers' self-evaluation showed very limited use of inclusive teaching strategies. This is mainly because currently, the idea of inclusive education has the most influence in elementary and middle school education in China. For the most part, inclusive higher education has not been a key topic for discussion. Furthermore, most university teachers have never encountered the challenges of teaching SwDs before due to the limited number of SwDs in regular universities. Therefore, university teachers lack an understanding of the special needs of SwDs, and lack inclusive teaching and adaptation strategies.

Tincani's study (2004) analyzed the reasons why SwDs have failed in higher education and found that the teaching strategies of university teachers might just be the key factor. He pointed out that teachers' responsiveness to inclusive education and to daily teaching repetition directly influenced the participation and enrollment of SwDs. Based on this finding, he put forward ten strategies which would help include SwDs, such as barrier-free teaching plans, individualized learning objectives, learning guides, regular tests, mentoring activities, tips for notes, peer coaching, timely feedback. His study revealed that university teachers need to know more about the basic special needs of SwDs and basic adaptations before they practice inclusive education.

\section{Conclusions and Suggestions}

This research has explored the overall attitudes of university teachers in China toward inclusive higher education of SwD from the three aspects of emotional, cognitive, and conative. In conclusion, respondents in this study maintained a morally positive attitude, namely positive emotion and cognition, toward the rights of SwDs to receive higher education, but not to inclusive higher education in regular universities. However, at the conative level, they lacked the inner incentive to practice inclusive higher education on one hand, and lacked the relevant knowledge, skills and strategies to cope with students' unique needs on the other hand. Suggestions of changing teacher attitudes should include the following measures:

First, Chinese universities should reinforce the relevant marketing of inclusive education, and dispense information through flyers, lectures or seminars. This would help to increase teachers' knowledge about inclusive higher education and aid in shifting their appreciation to encompass such diversity and difference as an opportunity for development rather than a cause for concern.

Secondarily, universities should pay more attention to providing teachers with information to help adjust their attitudes more positively toward inclusive higher education. In addition to refining their understanding of the idea of inclusive education, universities should develop some practical and feasible protocols to provide adequate accommodations to SwDs, such as flexible exam forms and extended examination time. To achieve these aims, universities should hold lectures and seminars regularly, in addition to distributing flyers and brochures, to help teachers and other students increase their awareness and understanding of special needs, and to develop compassion towards SwDs.

Additionally, university teachers thought leaders and service centers for SwDs play a very significant role during the development of inclusive universities. Therefore, leaders of universities need to initially adjust their insights and pay more attention to inclusive higher education, and then to endorse the establishment of service centers for SwDs. As we mentioned above, service centers for SwDs are still a new idea in China, and in the Chinese situation, attitudes of leaders might be very crucial to the willingness of universities to make appropriate systematic changes.

Moreover, we can't require every regular university teacher to be an expert in special education, or for every university to develop majors designed specifically to enroll $\mathrm{SwDs}$, so it would be more practical to set up a support system for teaching staff, where professionals with a range of disciplinary backgrounds, such as special education, social work, medical science and rehabilitation, can be hired to consult with teachers who teach SwDs in their classes. Such professionals could organize various activities to enhance public recognition of disability issues and to sponsor increased participation of SwDs in university life.

\section{Limitations}

Because of the small scope of this study, there are some limitations that should be addressed in future research. 
One limitation is that questionnaires can be subject to a social desirability effect. It is therefore recommended that they be accompanied by in-person interviews when possible to provide additional information regarding participants' real attitudes as expressed through facial expressions, non-verbal language, and so on. Additionally, this questionnaire survey has been already administered in Germany, Spain, U.S and Taiwan, so a comparative study between China and these countries and regions can be useful to identify differences in different cultural contexts, and to further study the cause of these differences. Furthermore, as the sample size is significantly small, future research should include a larger sample.

\section{Disclosure Statement}

No financial interest or benefit arises from the direct application of this research.

\section{References}

Angermeyer, M. C., \& Matschinger, H. (2005). Causal beliefs and attitudes to people with schizophrenia: Trend analysis based on data from two population surveys in Germany. The British Journal of Psychiatry, 186(4), 331-334. https://doi.org/10.1192/bjp.186.4.331

Ashman, A. F. (1984). Assessing student teachers' attitudes toward mentally retarded and physically handicapped persons. International Journal of Rehabilitation Research, 7(4), 434-438. http://dx.doi.org/10.1097/00004356-198412000-00009

Baggett, D. (1994). A study of faculty awareness of students with disabilities. Paper presented at the 18th Annual Conference of the National Association for Developmental Education, Kansas City, March 4. Retrieved from https://eric.ed.gov/?id=ED369208

Berry, G., \& Mellard, D. (2002). Current status on accommodating students with disabilities in selected community and technical colleges: Fall 1999-Spring 2001. Lawrence: University of Kansas.

Bian, L., Teng, X. D., \& Zhang, H. C. (2012). On the current professionalization of teachers in higher education for students with disabilities in China-An investigation report from four universities. Chinese Journal of Special Education, 11, 9-12. https://doi.org/10.3969/j.issn.1007-3728.2012.11.002

Bourke, A. B., Strehorn, K. C., \& Silver, P. (2000). Faculty members' provision of instructional accommodations to students with learning disability. Journal of Learning Disabilities, 33(1), 26-32.

https://doi.org/10.1177/002221940003300106

Burgstahler, S., Duclos, R., \& Turcotte, M. (2000). Preliminary findings: Faculty, teaching assistant, and student perceptions regarding accommodating students with disabilities in postsecondary environments. Seattle: University of Washington.

Chinese Ministry of Education (2015). Mid-term evaluation of "National Program for Medium- and Long-Term Educational Reform and Development"- Thematic evaluation report on special education. Retrieved from http://moe.gov.cn/jyb_xwfb/xw_fbh/moe_2069/xwfbh_2015n/xwfb_151130/151130_sfcl/201511/t2015113 0_221728.html, retrieved on 2017-07-29

Chu, H. B., \& Xu, M. (2007). Necessary condition to develop inclusive education for visually disabled college students. Journal of Changchun University, 3, 63-65. Retrieved from https://wenku.baidu.com/view/fbf2769f710abb68a98271fe910ef12d2bf9a905.html

Cook, B. G., Tankersley, M., Cook, L., \& Landrum, T. J. (2000). Teachers' attitudes toward their included students with disabilities. Exceptional Children, 67(1), 115-135. https://doi.org/10.1177/001440290006700108

Cook, B. G. (2001). A comparison of teachers' attitudes toward their included students with mild and severe disabilities. The Journal of Special Education, 34(4), 203-213. https://doi.org/10.1177/002246690103400403

Farmer, M., Riddick, B., \& Sterling, C. (2002). Dyslexia and inclusion: Assessment and support in higher education. London: Whurr Publishers.

Gitlow, L. (2001). Occupational therapy faculty attitudes toward the inclusion of students with disabilities in their educational programs. Occupational Therapy Journal of Research, 21(2), 115-131. https://doi.org/10.1177/153944920102100206

Hadjikakou, K., \& Hartas, D. (2008). Higher education provision for students with disabilities in Cyprus. Higher Education, 55, 103-119. https://doi.org/10.1007/s10734-007-9070-8 
Hanafin, J., Shevlin, M., Kenny, M., \& Mc Neela, E. (2007). Including young people with disabilities: Assessment challenges in higher education. Higher Education, 54, 435-448. https://doi.org/10.1007/s10734-006-9005-9

Ju, L. X. (2014). Research on supporting strategies for inclusive higher education of students with disabilities. Time Education, 19, 93-95. https://doi.org/10.3969/j.issn.1672-8181.2014.19.066

Link, B. G., Phelan, J. C., Bresnahan, M., Stueve, A., \& Pescosolido, B. A. (1999). Public conceptions of mental illness: labels, causes, dangerousness, and social distance. American Journal of Public Health, 89(9), 1328-1333. Retrieved from https://ajph.aphapublications.org/doi/pdf/10.2105/AJPH.89.9.1328

Ma, Y. (2014). Research on the supporting system of inclusive higher education for people with disability in China. (Doctoral dissertation). Nanjing Normal University. Available from the database of CNKI.

Palmer, D. S., Fuller, K., Arora, T., \& Nelson, M. (2001). Taking sides: Parents' views on inclusion for their children with severe disabilities. Exceptional Children, 67, 467-484. https://doi.org/10.1177/001440290106700403

Rao, S. (2004). Faculty attitudes and students with disabilities in higher education: A literature review. College Student Journal, 38(2), 191-198. Retrieved from http://jpllnet.sfsu.edu/login?url=http://search.ebscohost.com/login.aspx?direct=true\&AuthType=ip,cookie,u rl,uid\&db=ehh\&AN=14098753\&site=ehost-live

Rao, S., \& Gartin, B. C. (2003). Attitudes of university faculty toward accommodations to students with disabilities. Journal for Vocational Special Needs Education, 25(2), 47-54. Retrieved from https://files.eric.ed.gov/fulltext/EJ854908.pdf

Riddell, S., Weedon, E., Fuller, M., Healey, M., Hurst, A. Kelly, K., \& Piggott, L. (2007). Managerialism and equalities: tensions within widening access policy and practice for disabled students in UK universities. Higher Education, 54(4), 615-628. https://doi.org/10.1007/s10734-006-9014-8

Salend, S. J., \& Duhaney, L. M. G. (1999). The impact of inclusion on students with and without disabilities and their educators. Remedial and Special Education, 20(2), 114-126. https://doi.org/10.1177/074193259902000209

Sánchez, M. T. P., Fernández-Jiménez, C., \& Cabezas, M. F. (2018). The attitudes of different partners involved in higher education towards students with disabilities. International Journal of Disability, Development and Education, 65(4), 442-458. https://doi.org/10.1080/1034912X.2017.1406066

Standardization Administration of the P.R.C. (2011). Classification and Grading Criteria of Disability (GB/T 26341-2010). Retrieved from http://www.gzdpf.org.cn/Article/UploadFiles/201703/2017033109305961.pdf

Sweener, K., Kundert, D., May, K., \& Quinn, K. (2002). Comfort with accommodations at the community college level. Journal of Developmental Education, 25(3), 12-18. Retrieved from https://search-proquest-com.jpllnet.sfsu.edu/docview/228444682?accountid=13802

Teng, X. D. (2011). On the Faculty Building in Higher Education for Students with Disabilities in China. Chinese Journal of Special Education, 10, 9-12. https://doi.org/10.3969/j.issn.1007-3728.2011.10.002

Tincani M. (2004). Improving Outcomes for College Students with Disabilities: Ten Strategies for Instructors. College Teaching, 52(4), 128-133. https://doi.org/10.3200/CTCH.52.4.128-133

Triandis, H. C. (1971). Attitude and attitude change. New York, NY: John Wiley \& Sons.Vasek, D. (2005). Assessing the knowledge base of faculty at a private, four-year institution. College Student Journal, 39(2), 307-315. Retrieved from

http://jpllnet.sfsu.edu/login?url=http://search.ebscohost.com/login.aspx?direct=true\&AuthType=ip,cookie,u rl,uid\&db=eft\&AN=507805136\&site=ehost-live

Villarreal, P. (2002). Faculty knowledge of disability law: Implications for higher education practice. Waco, TX: Baylor University.

Vogel, S. A., Leyser, Y., Wyland, S., \& Brulle, A. (1999). Students with learning disabilities in higher education: Faculty attitude and practices. Learning Disabilities Research \& Practice, 14(3), 173-187. Retrieved from http://jpllnet.sfsu.edu/login?url=http://search.ebscohost.com/login.aspx?direct=true\&AuthType=ip,cookie,u rl,uid\&db=ehh\&AN=3349404\&site=ehost-live

Wang, M., Thomas, K. R., Chan, F. et al. (2003). A conjoint analysis of factors influencing American and Taiwanese college students' preferences for people with disabilities. Rehabilitation Psychology, 48(3), 
195-201. http://dx.doi.org.jpllnet.sfsu.edu/10.1037/0090-5550.48.3.195

Wilson, K., Getzel, E., \& Brown, T. (2000). Enhancing the postsecondary campus climate for students with disabilities. Journal of Vocational Rehabilitation, 14(1), 37-50. Retrieved from https://thinkcollege.net/sites/default/files/files/resources/Wilson_enhancing.pdf

Wolman, C., McCrink, C. S., Rodriguez, S. F., \& Harris-Looby, J. (2004). The Accommodation of University Students with Disabilities Inventory (AUSDI): Assessing American and Mexican faculty attitudes toward students with disabilities. Journal of Hispanic Higher Education, 3(3), 284-295. https://doi.org/10.1177/1538192704265985

Wu, D. G. (2001). The system roots of the modern university. Mordern Univeristy Education, 3, 17-19. https://doi.org/10.3969/j.issn.1671-1610.2001.03.007

Xu, T. W. (2008). Orientation of University Leaders' Responsibilities. Education Research, 10, 87-90. Retrieved from http://www.wanfangdata.com.cn/details/detail.do?_type=perio\&id=NSSD201403250000656360

Zhang, D., Landmark, L., Reber, A., Hsu, H. Y., Kwok, Oi-man, \& Benz, M. (2010). University faculty knowledge, beliefs, and practices in providing reasonable accommodations to students with disabilities. Remedial and Special Education, 31(4), 276-286. https://doi.org/10.1177/0741932509338348

Zong, Z. G. (2005). On a thinking of several problems of disabled person's higher education. Journal of Changchun University, 15(1), 1-4. https://doi.org/10.3969/j.issn.1009-3907-B.2005.01.001

\section{Notes}

Note 1. "Regular university" refers to universities that originally only serve students without disabilities in the Chinese. Before 1980s, nearly no students with disabilities could gain access to higher education in China. Since 1980s, a few colleges have been gradually established to specifically recruit students with disabilities; these are called "special education colleges." Nowadays, special education colleges accept also students without disabilities to study related majors such as special education.

Note 2. Susanne Peschke developed and used this instrument for her doctoral dissertation. And she got her PhD degree in 2017. E-mail: susanne.peschke@uni-hamburg.de

Note 3. In some provinces of China, students with artistic or sports specialties can be awarded extra points on the national university entrance examination.

\section{Copyrights}

Copyright for this article is retained by the author(s), with first publication rights granted to the journal.

This is an open-access article distributed under the terms and conditions of the Creative Commons Attribution license (http://creativecommons.org/licenses/by/4.0/). 